\title{
Canadian College of Neuropsychopharmacology 2018 award winners
}

\section{Heinz Lehmann Award}

Dr. Alan Evans is the recipient of the 2018 Canadian College of Neuropsychopharmacology (CCNP) Heinz Lehmann Award. Dr. Evans is a Professor of Neurology/ Neurosurgery, Psychiatry, Biomedical Engineering and Medical Physics at McGill University. He is also the Director of the Montreal Consortium for Imagining Research and Co-Director of the Ludmer Centre for Neuroinformatics and Mental Health at McGill University. This award is designed to recognize outstanding research achievements by Canadian scientists in the field of neuropsychopharmacology, and this year the award is for clinical/translational research. The award, donated by Pfizer Canada Inc., consists of a $\$ 2000$ honorarium and a suitably engraved plaque. Congratulations to Dr. Evans!

\section{Young Investigator Award}

Dr. Isabelle Boileau and Dr. Stephanie Borgland are each recipients of the 2018 CCNP Young Investigator Award. Dr. Boileau is a Clinical Research Scientist and Head of the Addiction Imaging Research Group at the Centre for Addiction and Mental Health in Toronto, Ontario, and an Associate Professor at the University of Toronto in the Department of Psychiatry. Dr. Borgland is an Associate Pro- fessor in the Hotchkiss Brain Institute in the Department of Anesthesiology, Pharmacology \& Therapeutics at the University of British Columbia. The award, donated by Pfizer Canada Inc., consists of a $\$ 2000$ honorarium and a suitably engraved plaque. Congratulations to both Dr. Boileau and Dr. Borgland!

\section{CCNP Medal}

Dr. Patricia Boksa is the recipient of the 2018 CCNP Medal. Dr. Boksa is a Full Professor in the Department of Psychiatry at McGill University and is also an Associate Member of the Department of Neurology and Neurosurgery. Dr. Boksa was the first female CCNP President, and she also currently serves as Co-Editor in Chief of the Journal of Psychiatry and Neuroscience. This award, sponsored by the CCNP, consists of a bronze medal engraved with the name of the recipient. Congratulations to Dr. Boksa!

These awards will be conferred at the 41st Annual CCNP Meeting in Vancouver, British Columbia, June 28-30, 2018. The conference will be held in downtown Vancouver at UBC Robson Square.

DOI: 10.1503/jpn.180055 